ISSN : 2615-1995, E-ISSN : 2615-0654

J. Madani., Vol. 1, No. 2, September 2018 (417-429)

(C)2018 Lembaga Kajian Demokrasi

MADANI

dan Pemberdayaan Masyarakat (LKD-PM)

\title{
PENDEKATAN MODEL MARKOV SWITCHING PADA PASAR MODAL INDONESIA
}

\author{
Iman Lubis \\ Fakultas Ekonomi, Universitas Pamulang \\ Dosen01479@unpam.ac.id
}

\begin{abstract}
Abstrak
Penelitian ini memastikan kebenaran bahwa pasar modal Indonesia merupakan pasar saham terkecil resikonya atau pasar yang stabil. Pendekatan metode pada penelitian ini adalah pendekatan Markov Switching Regime Model. Data yang digunakan adalah data harian dari tahun 1990 sampai 2018. Jumlah data disesuaikan dengan dimulainya indeks pasar. Hasilnya adalah hampir semua indeks tidak direkomendasikan selain indeks development board, indeks miscellaneous industry, indeks ftse Indonesia, indeks LQ-45, indeks 30 saham, dan indeks shariah.
\end{abstract}

Kata Kunci: Markov Switching, pasar modal Indonesia, investasi stabil

\section{PENDAHULUAN}

\section{Latar Belakang}

Isu kestabilan investasi sangat menentukan prilaku investor dalam mengambil keputusan. Semakin tidak stabil sebuah investasi dalam menghasilkan return semakin tidak percaya investor untuk menaruh uangnya pada keranjang tersebut. Oleh sebab itu, penelitian ini ditujukan untuk mengetahui sebarapa tidak stabilnya pasar modal Indonesia sehingga sangat sensitif berpengaruh dari variable lain. Ketidakstabilan ini bisa memicu kerugian besar jika ada unsur dari luar yang mempengaruhi pergerakan dari nilai harga pasar saham.

(Basher, Haug, \& Sadorsky, 2018) Penelitian ini menganalisa perubahan harga minyak pada pasar modal negara-negara pengekspor minyak. Perubahan harga minyak memiliki dampak yang signifikan untuk membangun porofolio investasi investor. Hasil dari metode Markov strategi transkasi beli dan tahan adalah yang terbaik.

(Zhu, Su, You, \& Ren, 2017) Penelitian ini menemukan bahwa harga minyak sedikit mempengaruhi pada volatilitas rendah saham dan mempengaruhi volatilitas tinggi. Permintaan minyak lebih besar mempengaruhi pasar saham dibandingkan penawaran minyak.

(Roubaud \& Arouri, 2018) Penelitian ini mencari interaksi antara harga minyak, nilai tukar, dan pasar modal. Penelitian ini mempertimbangkan ketidakpastian kebijakan ekonomi. Alat analisa yang digunakan adalah model VAR dan MS-VAR. Hasilnya adalah adanya hubungan antara minyak, mata uang dan mata uang.

(Liu \& Maheu, 2018) Penelitian ini menggabungkan return saham dan ex-post variance di dalam kerangka markov switching. Hasilnya adalah penggabungan model tersebut menghasilkan prediksi yang lebih baik.

(Zotoloy, Federickson, \& Lyon, 2017) Penelitian ini meneruskan dokumentasi dari hubungan pengembalian pendapatan keseluruhan yang negatif di masa depan. Penelitian ini menggunakan metode markov. Hasilnya adalah menghasilkan makroekomi dan kondisi keuangan mempengaruhi keseluruhan pendapatan di masa depan lebih negatif dan sedikit positif 
Pasar saham Nigeria menggunakan Markov Switching Vector Autoregressive (MSVAR) untuk menguji kestabilannya. Data yang digunakan dari 1985-2014 dan model MSVAR menangkap adanya perubahan mendadak dari variable yang tidak diamati sehingga sangat direkomendasikan bagi investor untuk berhati hati pada pasar saham tersebut.

Pada penelitian ini peneliti tertarik untuk mengetahui kestabilan dan ketidakstabilan dari pasar modal di Indonesia. Faktanya, penelitian terbaru menemukan adanya hubungan antara harga minyak dan mata uang terhadap pasar modal. Peneliti sadar pentingnya mencari pengaruh tersebut namun pada penelitian ini peneliti ingin mencari pengaruh dua rezim dan durasi masing-masing rezim.

\section{Rumusan Masalah}

1. Seberapa besarkah pengaruh rezim satu dan dua terhadap pergerakan pasar saham di Indonesia?

2. Seberapa panjangkah durasi dan ekspektasi dari masing masing rezim satu dan dua?

\section{Pembatasan Masalah}

1. Penelitian ini hanya membahas pasar modal di Indonesia.

2. Penelitian ini menggunakan data dari satu Januari 1990 sampai 20 Juli 2018. Jika data tidak dimulai sebelum satu Januari 1990 maka data dimulai dari waktu pertama terdaftar.

\section{Tujuan Penelitian}

1. Untuk mengetahui seberapa besar pengaruh rezim satu dan dua terhadap pergerakan pasar saham di Indonesia

2. Untuk mengetahui seberapa panjangkah durasi dan ekspektasi dari masing-masing rezim satu dan dua.

\section{Kerangka Pemikiran}

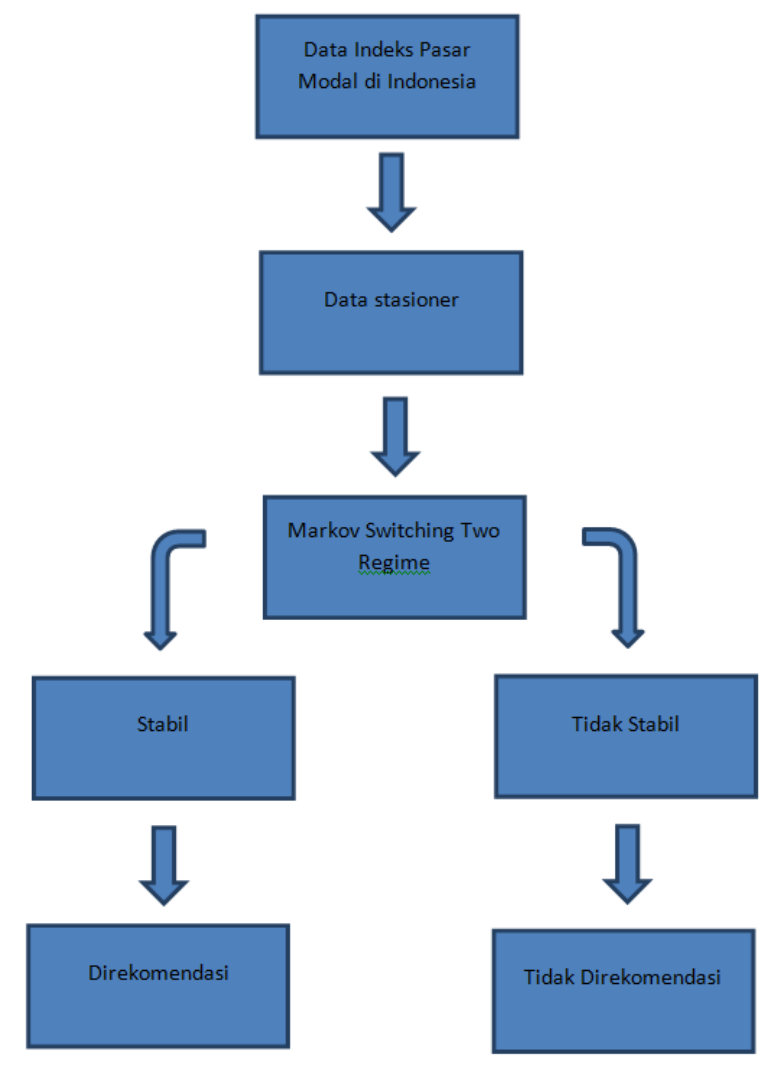

\section{Hipotesis}

$\mathrm{H} 0: \beta 1=0$ : Artinya tidak ada pengaruh rezim satu di pasar modal Indonesia

$\mathrm{H} 1: \beta 1 \neq 0$ : Artinya ada pengaruh rezim satu di pasar modal Indonesia

$\mathrm{H} 0: \beta 2=0$ : Artinya tidak ada pengaruh rezim dua di pasar modal Indonesia

$\mathrm{H} 1: \beta 2 \neq 0$ : Artinya ada pengaruh rezim dua di pasar modal Indonesia

\section{Tinjauan Pustaka}

Switching regression dimulai oleh Quandt (1958). Golfield dan Quandt (1973), dan Cosslett dan Lee (1985) meneliti switching regime dengan proses markov variabel lain yang tidak diamati. Pada (Hamilton, 1990) penelitian ini menggunakan EM algoritma untuk metode alternative switching regression.

Metode markov digunakan ketika adanya keadaan tiba tiba yang merubah kondisi keuangan seperti krisis moneter, perubahana kebijakan pemerintah sesuai dengan penelitian sebelumnya. Kesimpulan dua probabilitas adalah (Hamilton, Regime switching models, 2010)

$$
\varepsilon_{j t}=\operatorname{Pr}\left(s_{t}=j \mid \Omega_{t} ; \theta\right)
$$

Dimana $\mathrm{j}=1,2$, kedua probabilitas 
ini merupakan jumlah untuk menyatukan konstruksi. $\Omega_{\mathrm{t}}=\left\{\mathrm{y}_{\mathrm{t}}, \mathrm{y}_{\mathrm{t}^{-}}, \ldots, \mathrm{y}_{1}, \mathrm{y}_{2}\right\}$ mempunyai sekumpulan pengamatan pada waktu, dan $\theta$ adalah arah parameter populasi, contoh dari $\theta=$ $\left(\sigma, \phi, c_{1}, c_{2}, p_{11}, p_{22}\right)$ yang diketahui kepastiannya tanpa bukti pengujian.

\section{METODOLOGI PENELITIAN Sifat Penelitian}

Metode pada penelitian ini adalah metode deskriptif. Penelitian ini hanya menjabarkan fakta yang ada tanpa mencari hubungan satu dengan yang lain.

\section{Data Penelitian}

Data yang digunakan adalah indeks pasar modal yang ada di Indonesia. Menurut www. investing.com, indeks terbagi atas empat kategori yaitu:

\section{Indeks Utama}

\begin{tabular}{|c|l|c|c|}
\hline \multicolumn{1}{|c|}{ Indeks } & \multicolumn{1}{|c|}{ Variabel } & Waktu & Observasi \\
\hline IDX Composite & r jkse & $05 / 10 / 2000-20 / 07 / 2018$ & 4339 \\
\hline
\end{tabular}

\section{Sektor-sektor Primer}

\begin{tabular}{|c|c|c|c|}
\hline Indeks & Variabel & Waktu & Observasi \\
\hline IDX Agriculture & $\begin{array}{l}\text { return_- } \\
\text { agriculture }\end{array}$ & 09/10/2000 - 20/07/2018 & 4339 \\
\hline $\begin{array}{l}\text { IDX Basic In- } \\
\text { dustry }\end{array}$ & $\begin{array}{l}\text { r_basic_ } \\
\text { industry }\end{array}$ & 06/10/2000 - 20/07/2018 & 4338 \\
\hline $\begin{array}{l}\text { IDX Consumer } \\
\text { Industry }\end{array}$ & $\begin{array}{l}\text { r_consumer_ } \\
\text { industry }\end{array}$ & 09/10/2000 - 20/07/2018 & 2503 \\
\hline IDX Development & $\begin{array}{l}r_{-} \\
\text {development_ } \\
\text { board }\end{array}$ & 10/04/2002 - 20/07/2018 & 3973 \\
\hline IDX Finance & r_finance & 09/10/2000 - 20/07/2018 & 4339 \\
\hline IDX Infrastructure & r_infrastructure & 09/10/2000 - 20/07/2018 & 2423 \\
\hline IDX Manufacture & r_manufacture & 09/10/2000 - 20/07/2018 & 2503 \\
\hline IDX Mining & r_mining & 09/10/2000 - 20/07/2018 & 4339 \\
\hline IDX Misc-Industry & $\begin{array}{l}{ }_{-} \\
\text {miscellaneous } \\
\text { indu }\end{array}$ & 06/10/2000 - 20/07/2018 & 4339 \\
\hline IDX Property & r_property & 09/10/2000 - 20/07/2018 & 4339 \\
\hline IDX Trade & r_trade & $10 / 10 / 2000-20 / 07 / 2018$ & 4339 \\
\hline
\end{tabular}

\section{Indeks tambahan}

\begin{tabular}{|l|l|c|c|}
\hline \multicolumn{1}{|c|}{ Indeks } & \multicolumn{1}{c|}{ Variabel } & Waktu & Observasi \\
\hline FTSE Indonesia & r_ftse & $13 / 08 / 2001-20 / 07 / 2018$ & 4404 \\
\hline IDX Kompas 100 & r_kompas100 & $13 / 08 / 2007-20 / 07 / 2018$ & 2671 \\
\hline IDX PEFINDO-25 & R_pefindo_25 & 20/05/2009 - 20/07/2018 & 2247 \\
\hline IDX LQ45 & r_lq45 & $09 / 10 / 2000-20 / 07 / 2018$ & 4339 \\
\hline
\end{tabular}

4. Indeks Lainnya

\begin{tabular}{|l|l|c|c|}
\hline \multicolumn{1}{|c|}{ Indeks } & \multicolumn{1}{c|}{ Variabel } & Waktu & Observasi \\
\hline IDX 30 & return_idx30 & $24 / 04 / 2014-20 / 07 / 2018$ & 1526 \\
\hline IDX Banking & r_banking & $08 / 11 / 2012-20 / 07 / 2018$ & 1380 \\
\hline IDX BISNIS-27 & r_bisnis27 & $28 / 01 / 2009-20 / 07 / 2018$ & 2322 \\
\hline IDX Islamic & r_islamic & $06 / 10 / 2000-20 / 07 / 2018$ & 4338 \\
\hline IDX Main Board & r_main_board & $10 / 04 / 2002-20 / 07 / 2018$ & 3973 \\
\hline IDX SHARIAH & r_shariah & $13 / 05 / 2011-20 / 07 / 2018$ & 1761 \\
\hline IDX SRI-KEHATI & r_srikehati & $09 / 06 / 2009-20 / 07 / 2018$ & 2233 \\
\hline Investor33 & r_investor33 & $24 / 03 / 2014-20 / 07 / 2018$ & 1047 \\
\hline MNC36 & r_mnc36 & $29 / 03 / 2013-20 / 07 / 2018$ & 1186 \\
\hline Sminfra18 & r_sminfra 18 & $01 / 02 / 2013-20 / 07 / 2018$ & 1326 \\
\hline \multicolumn{4}{|c|}{} \\
\hline
\end{tabular}

\section{Analisis Data}

1. Return (Differensiasi) Indeks

Return indeks dilakukan untuk membuat data penelitian stasioner.

$\mathrm{H}_{0}$ : Terdapat unit root di series.

$\mathrm{H}_{1}$ : Tidak terdapat unit root di series atau data merupakan data stasioner.

Berikut rumus return atau differensiasi

$$
r_{t}=\ln \left(\frac{P_{t}}{P_{t-1}}\right)
$$

Dimana:

$\mathrm{r}_{\mathrm{t}} \quad=$ return saham

$\mathrm{P}_{\mathrm{t}}=$ Harga saat ini

$\mathrm{P}_{\mathrm{t}-1}=$ Harga sebelumnya

2. Metode Markov Switching 2 Regime
a. Regime 1
b. Regime 2
c. Durasi
d. ekspektasi

\section{HASIL PENELITIAN DAN PEMBAHASAN Hasil Penelitian}

\section{Indeks Utama}

\begin{tabular}{|l|l|c|c|}
\hline \multicolumn{4}{|c|}{ Tabel 1. ADF Unit Root Test Indeks Utama } \\
\hline \multirow{3}{*}{ Indeks Utama } & \multicolumn{1}{|c|}{ Variabel } & t-statistik & Prob.* $^{*}$ rjkse \\
\cline { 2 - 4 } & $\begin{array}{l}\text { Augmented Dickey-Fuller } \\
\text { Test Statistic }\end{array}$ & -59.16526 & 0.0001 \\
\cline { 2 - 4 } & Test Critical Values 5\% & -2.862010 & \\
\hline \multicolumn{3}{|c|}{ Sumber : Data Diolah Sendiri } \\
\hline
\end{tabular}


JURNAL MADANI: Ilmu Pengetahuan, Teknologi, dan Humaniora, Vol. 1, No. 2, September 2018: 417 - 429

\begin{tabular}{|c|c|c|c|c|}
\hline \multicolumn{5}{|c|}{ Tabel 2. Hasil Markov Switching Regime Indeks Utama } \\
\hline Parameter & Koefisien & Std. Error & z-Statistik & Prob. \\
\hline \multicolumn{5}{|c|}{ Regime 1 } \\
\hline C & -0.001501 & 0.000770 & -1.950449 & 0.0511 \\
\hline LOG(SIGMA) & -3.799911 & 0.033824 & -112.3432 & 0.0000 \\
\hline \multicolumn{5}{|c|}{2} \\
\hline C & 0.001371 & 0.000170 & 8.047173 & 0.0000 \\
\hline LOG (SIGMA) & -4.745649 & 0.024250 & -195.6988 & 0.0000 \\
\hline \multicolumn{5}{|c|}{ Sumber: Data Diolah Sendiri } \\
\hline
\end{tabular}

\begin{tabular}{|c|c|c|c|c|}
\hline \multicolumn{5}{|c|}{ Tabel 3. Transition Matrix Parameters Indeks Utama } \\
\hline Parameter & Koefisien & Std. Error & t-Statistik & Prob. \\
\hline P11-C & 2.224500 & 0.193364 & 11.50424 & 0.0000 \\
\hline P21-C & -3.484070 & 0.197684 & -17.62443 & 0.0000 \\
\hline \multicolumn{5}{|c|}{ Sumber : Data Diolah Sendiri } \\
\hline
\end{tabular}

Tabel 4. Probabilitas Transisi dan Durasi Harapan Indeks Utama Probabilitas Transisi

\begin{tabular}{|c|c|c|}
\hline & 1 & 2 \\
\hline 1 & 0.902428 & 0.097572 \\
\hline 2 & 0.029769 & 0.970231 \\
\hline Durasi Harapan & 1 & 2 \\
\hline & 178.5060 & 1.00012 \\
\hline & & Sumber: Data Diolah Sendiri \\
\hline
\end{tabular}

Indeks Sektor-sektor Primer

\begin{tabular}{|l|c|c|c|}
\hline \multicolumn{4}{|c|}{ Tabel 5. ADF Unit Root Test Indeks Sektor-sektor Primer } \\
\hline $\begin{array}{c}\text { Indeks Sektor-sektor } \\
\text { Primer }\end{array}$ & $\begin{array}{c}\text { Parameters } \\
\text { ADF Test 5\% }\end{array}$ & t-Statistik & Prob. ${ }^{*}$ \\
\hline return_agriculture & -2.862010 & -42.17168 & 0.0000 \\
\hline r_basic_industry & & -61.00314 & 0.0001 \\
\hline r_consumer_industry & -2.862495 & -49.16456 & 0.0001 \\
\hline r_development_board & -2.862071 & -58.44160 & 0.0001 \\
\hline r_finance & -2.862010 & -59.39255 & 0.0001 \\
\hline r_infrastructure & -2.862533 & -47.56488 & 0.0001 \\
\hline r_manufacture & -2.862495 & -48.32826 & 0.0001 \\
\hline r_mining & -2.862010 & -60.01060 & 0.0001 \\
\hline r_miscellaneous_indu & & -35.71278 & 0.0000 \\
\hline r_property & & -59.48354 & 0.0000 \\
\hline r_trade & -61.27599 & 0.0000 \\
\hline \multicolumn{4}{|c|}{ Sumber: Diolah Sendiri } \\
\hline
\end{tabular}

\begin{tabular}{|c|c|c|c|c|}
\hline \multicolumn{5}{|c|}{ Tabel 6. Hasil Markov Switching Regime Sektor-sektor Primer } \\
\hline Parameter & Koefisien & Std. Error & z-Statistik & Prob. \\
\hline \multicolumn{5}{|c|}{ return_agriculture } \\
\hline \multicolumn{5}{|c|}{ Regime 1 } \\
\hline C & 0.000065 & 0.000235 & 0.276316 & 0.7823 \\
\hline LOG(SIGMA) & -4.489978 & 0.025023 & -218.3900 & 0.0000 \\
\hline
\end{tabular}

\begin{tabular}{|c|c|c|c|c|}
\hline \multicolumn{5}{|c|}{ Regime 2} \\
\hline C & 0.002075 & 0.000935 & 2.218179 & 0.02635 \\
\hline LOG (SIGMA) & -3.402745 & 0.025023 & -135.9859 & 0.0000 \\
\hline \multicolumn{5}{|c|}{ r_basic_industry } \\
\hline \multicolumn{5}{|c|}{ Regime 1} \\
\hline C & -0.001551 & 0.000978 & -1.585018 & 0.1130 \\
\hline LOG(SIGMA) & -3.620394 & 0.036610 & -98.89138 & 0.0000 \\
\hline \multicolumn{5}{|c|}{ Regime 2} \\
\hline c & 0.001298 & 0.000218 & 5.966488 & 0.0000 \\
\hline LOG(SIGMA) & -4.489792 & 0.036610 & -98.89138 & 0.0000 \\
\hline \multicolumn{5}{|c|}{ r_consumer_industry } \\
\hline \multicolumn{5}{|c|}{ Regime 1} \\
\hline C & 0.058512 & 0.057238 & 1.022255 & 0.3067 \\
\hline LOG(SIGMA) & -1.1111282 & 0.136612 & -8.134571 & 0.0000 \\
\hline \multicolumn{5}{|c|}{ Regime 2} \\
\hline 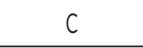 & 0.000847 & 0.000266 & 3.178788 & 0.0015 \\
\hline LOG(SIGMA) & -4.341761 & 0.016558 & -262.2131 & 0.0000 \\
\hline \multicolumn{5}{|c|}{ I_development_board } \\
\hline \multicolumn{5}{|c|}{ Regime 1} \\
\hline C & 0.001055 & 0.000144 & 7.327012 & 0.0000 \\
\hline LOG(SIGMA) & -4.996596 & 0.026073 & -191.64818 & 0.0000 \\
\hline \multicolumn{5}{|c|}{ Regime 2} \\
\hline c & 0.000973 & 0.000156 & 6.237425 & 0.0000 \\
\hline LOG(SIGMA) & -4.935654 & 0.027246 & -181.1496 & 0.0000 \\
\hline \multicolumn{5}{|c|}{ r_finance } \\
\hline \multicolumn{5}{|c|}{ Regime 1} \\
\hline c & 0.001045 & 0.000207 & 5.044661 & 0.0000 \\
\hline LOG(SIGMA) & -4.676198 & me0.026553 & -176.1055 & 0.0000 \\
\hline \multicolumn{5}{|c|}{ Regime 2} \\
\hline C & 0.000621 & 0.000570 & 1.089555 & 0.2759 \\
\hline LOG(SIGMA) & -3.797280 & 0.025865 & -146.8132 & 0.0000 \\
\hline \multicolumn{5}{|c|}{ r_infirastructure } \\
\hline \multicolumn{5}{|c|}{ Regime 1} \\
\hline C & 0.006048 & 0.004647 & 1.301301 & 0.1932 \\
\hline LOG(SIGMA) & -2.904655 & 0.095786 & -30.32455 & 0.0000 \\
\hline \multicolumn{5}{|c|}{ Regime 2} \\
\hline C & 0.000841 & 0.000399 & 2.105109 & 0.0353 \\
\hline LOG(SIGMA) & -4.076356 & 0.030141 & -135.2411 & 0.0000 \\
\hline \multicolumn{5}{|c|}{ r_manufacture } \\
\hline \multicolumn{5}{|c|}{ Regime 1} \\
\hline C & 0.001024 & 0.000260 & 3.933379 & 0.0001 \\
\hline LOG(SIGMA) & -4.371601 & 0.017160 & -254.7521 & 0.0000 \\
\hline \multicolumn{5}{|c|}{ Regime 2} \\
\hline$C$ & 0.022959 & 0.034116 & 0.672970 & 0.5010 \\
\hline LOG(SIGMA) & -1.552219 & 0.135265 & -11.47540 & 0.0000 \\
\hline \multicolumn{5}{|c|}{ r_mining } \\
\hline \multicolumn{5}{|c|}{ Regime 1} \\
\hline C & 0.002264 & 0.001291 & 1.754258 & 0.0794 \\
\hline LOG(SIGMA) & -3.328309 & 0.041430 & -80.33487 & 0.0000 \\
\hline
\end{tabular}


JURNAL MADANI: Ilmu Pengetahuan, Teknologi, dan Humaniora, Vol. 1, No. 2, September 2018: 417 - 429

\begin{tabular}{|c|c|c|c|c|}
\hline \multicolumn{5}{|c|}{ Regime 2} \\
\hline C & 0.000421 & 0.000272 & 1.547645 & 0.1217 \\
\hline LOG(SIGMA) & -4.377384 & 0.031041 & -141.0205 & 0.0000 \\
\hline \multicolumn{5}{|c|}{ r_miscellaneous_indu } \\
\hline \multicolumn{5}{|c|}{ Regime 1} \\
\hline C & 0.000455 & 0.000269 & 1.689556 & 0.0977 \\
\hline LOG(SIGMA) & -4.274376 & 0.025397 & -168.3030 & 0.0000 \\
\hline \multicolumn{5}{|c|}{ Regime 2} \\
\hline C & 0.001915 & 0.001157 & 1.656029 & 0.0977 \\
\hline LOG(SIGMA) & -3.424537 & 0.035700 & -95.92648 & 0.0000 \\
\hline \multicolumn{5}{|c|}{ r_property } \\
\hline \multicolumn{5}{|c|}{ Regime 1} \\
\hline C & 0.000626 & 0000869 & 0.720892 & 0.4710 \\
\hline LOG(SIGMA) & -3.646611 & 0.032257 & -113.0485 & 0.0000 \\
\hline \multicolumn{5}{|c|}{ Regime 2} \\
\hline C & 0.000768 & 0.000198 & 3.871380 & 0.0001 \\
\hline LOG(SIGMS) & -4601555 & 0.021565 & -213.3842 & 0.0000 \\
\hline \multicolumn{5}{|c|}{ It trade } \\
\hline \multicolumn{5}{|c|}{ Regime 1} \\
\hline C & 0.001068 & 0.000169 & 6.332059 & 0.0000 \\
\hline LOG(SIGMA) & -4.694064 & 0.017498 & -268.2676 & 0.0000 \\
\hline \multicolumn{5}{|c|}{ Regime 2} \\
\hline C & -0.001515 & 0.0008222 & -1.844025 & 0.0652 \\
\hline LOG(SIGMA) & -3.774536 & 0.032031 & -117.8400 & 0.0000 \\
\hline \multicolumn{5}{|c|}{ Sumber : Data Diolah Sendiri } \\
\hline
\end{tabular}

\begin{tabular}{|c|c|c|c|c|}
\hline \multicolumn{5}{|c|}{ Tabel 7. Transition Matrix Parameters Indeks Sektor-Sektor Primer } \\
\hline Parameter & Koefisien & Std. Error & t-Statistik & Prob. \\
\hline P11-C & 3.110978 & 0.144950 & 21.46238 & 0.0000 \\
\hline P21-C & -2.281697 & 0.025023 & -135.9859 & 0.0000 \\
\hline \multicolumn{5}{|c|}{ r_basic_industry } \\
\hline P11-C & 2.067782 & 0.1841188 & 11.22647 & 0.0000 \\
\hline P21-C & -3.457332 & 0.184188 & 11.22647 & 0.0000 \\
\hline \multicolumn{5}{|c|}{ r_consumer_industry } \\
\hline P11-C & -0.149877 & 0.439981 & -0.340643 & 0.7334 \\
\hline P21-C & -4.906438 & 0.292867 & -1675315 & 0.0000 \\
\hline \multicolumn{5}{|c|}{ r_development_board } \\
\hline P11-C & 3.726714 & 0.193644 & 19.24521 & 0.0000 \\
\hline P21-C & -2.979422 & 0.216600 & -13.75538 & 0.0000 \\
\hline \multicolumn{5}{|c|}{ r_finance } \\
\hline P11-C & 3.169551 & 0.174524 & 18.16108 & 0.0000 \\
\hline P21-C & -2.679004 & 0.192676 & -13.90418 & 0.0000 \\
\hline \multicolumn{5}{|c|}{ r_infirastructure } \\
\hline P11-C & 3.481313 & 0.27164 & 12.81549 & 0.0000 \\
\hline P21-C & -1.294193 & 0.290847 & -4.449732 & 0.0000 \\
\hline P11-C & 4.885666 & 0.315911 & 15.46532 & 0.0000 \\
\hline P21-C & -0.003376 & 0.483367 & -0.006985 & 0.0000 \\
\hline
\end{tabular}

\begin{tabular}{|c|c|c|c|c|}
\hline \multicolumn{5}{|c|}{ r_mining } \\
\hline P11-C & 2.889985 & 0.219218 & 13.18314 & 0.0000 \\
\hline P21-C & -4.016822 & 0.197001 & -20.38982 & 0.0000 \\
\hline \multicolumn{5}{|c|}{ r_miscellaneous_indu } \\
\hline P11-C & 3.412131 & 0.237868 & 14.34463 & 0.0000 \\
\hline P21-C & -2.031409 & 0.207031 & -9.812092 & 0.0000 \\
\hline \multicolumn{5}{|c|}{ r_property } \\
\hline P11-C & 2.195642 & 0.174405 & 12.58932 & 0.0000 \\
\hline P21-C & -3.443070 & 0.174410 & -19.74121 & 0.0000 \\
\hline & r_trade \\
\hline P11-C & 3.897708 & 0.179785 & 21.67988 & 0.0000 \\
\hline P21-C & -2.504702 & 0.185834 & -13.47818 & 0.0000 \\
\hline &
\end{tabular}

\begin{tabular}{|c|c|c|}
\hline \multicolumn{3}{|c|}{$\begin{array}{l}\text { Tabel 8. Probabilitas Transisi dan Durasi Harapan } \\
\text { Indeks Sektor-sektor Primer }\end{array}$} \\
\hline \multicolumn{3}{|c|}{ Return_agiculture } \\
\hline Probabilitas Transisi & 1 & 2 \\
\hline 1 & 0.957343 & 0.042657 \\
\hline 2 & 0.092650 & 0.907350 \\
\hline Durasi Harapan & 1 & 2 \\
\hline & 23.44297 & 10.79328 \\
\hline \multicolumn{3}{|c|}{ R_basic_industry } \\
\hline Probabilitas Transisi & 1 & 2 \\
\hline 1 & 0.887732 & 0.112268 \\
\hline 2 & 0.030551 & 0.969449 \\
\hline Durasi Harapan & 1 & 2 \\
\hline & 8.907267 & 32.73221 \\
\hline \multicolumn{3}{|c|}{ R_consumer_industry } \\
\hline Probabilitas Transisi & 1 & 2 \\
\hline 1 & 0.462601 & 0.537399 \\
\hline 2 & 0.007344 & 0.992656 \\
\hline Durasi Harapan & 1 & 2 \\
\hline & 1.860814 & 136.1571 \\
\hline \multicolumn{3}{|c|}{ r_development_board } \\
\hline Probabilitas Transisi & 1 & 2 \\
\hline 1 & 0.976494 & 0.023506 \\
\hline 2 & 0.048364 & 0.951636 \\
\hline Durasi Harapan & 1 & 2 \\
\hline & 42.54236 & 20.67645 \\
\hline \multicolumn{3}{|c|}{ r_finance } \\
\hline Probabilitas Transisi & 1 & 2 \\
\hline 1 & 0.959672 & 0.040328 \\
\hline 2 & 0.064224 & 0.935776 \\
\hline Durasi Harapan & 1 & 2 \\
\hline & 24.79679 & 15.57058 \\
\hline \multicolumn{3}{|c|}{ r_infrastructure } \\
\hline Probabilitas Transisi & 1 & 2 \\
\hline 1 & 0.970151 & 0.029849 \\
\hline
\end{tabular}


JURNAL MADANI: Ilmu Pengetahuan, Teknologi, dan Humaniora, Vol. 1, No. 2, September 2018: 417 - 429

\begin{tabular}{|c|c|c|}
\hline 2 & 0.215144 & 0.784856 \\
\hline Durasi Harapan & 1 & 2 \\
\hline & 33.50238 & 4.648051 \\
\hline \multicolumn{3}{|c|}{ r_manufacture } \\
\hline Probabilitas Transisi & 1 & 2 \\
\hline 1 & 0.992503 & 0.007497 \\
\hline 2 & 0.499156 & 0.500844 \\
\hline \multirow[t]{2}{*}{ Durasi Harapan } & 1 & 2 \\
\hline & 133.3786 & 2.003382 \\
\hline \multicolumn{3}{|c|}{$r_{-} \operatorname{mining}$} \\
\hline Probabilitas Transisi & 1 & 2 \\
\hline 1 & 0.947349 & 0.052651 \\
\hline 2 & 0.017691 & 0.982309 \\
\hline \multirow[t]{2}{*}{ Durasi Harapan } & 1 & 2 \\
\hline & 18.99304 & 56.52435 \\
\hline \multicolumn{3}{|c|}{ r_miscellaneous_indu } \\
\hline Probabilitas Transisi & 1 & 2 \\
\hline 1 & 0.968082 & 0.031918 \\
\hline 2 & 0.115944 & 0.884056 \\
\hline \multirow[t]{2}{*}{ Durasi Harapan } & 1 & 2 \\
\hline & 31.32980 & 8.624824 \\
\hline \multicolumn{3}{|c|}{ r_property } \\
\hline Probabilitas Tansisi & 1 & 2 \\
\hline 1 & 0.899857 & 0.100143 \\
\hline 2 & 0.030976 & 0.969024 \\
\hline \multirow[t]{2}{*}{ Durasi Harapan } & 1 & 2 \\
\hline & 9.985765 & 32.28285 \\
\hline \multicolumn{3}{|c|}{ r_trade } \\
\hline Probabilitas Transisi & 1 & 2 \\
\hline 1 & 0.980115 & 0.019885 \\
\hline 2 & 0.075529 & 0.924471 \\
\hline \multirow[t]{2}{*}{ Durasi Harapan } & 1 & 2 \\
\hline & 50.28933 & 13.23991 \\
\hline & & Sumber : Data Dio \\
\hline
\end{tabular}

\section{Indeks Tambahan}

\begin{tabular}{|l|c|c|c|}
\hline \multicolumn{4}{|c|}{ Tabel 9. ADF Unit Root Test Indeks Tambahan } \\
\hline $\begin{array}{c}\text { Indeks Sektor-sektor } \\
\text { Primer }\end{array}$ & $\begin{array}{c}\text { Parameters } \\
\text { ADF Test 5\% }\end{array}$ & t-Statistik & Prob. $^{*}$ \\
\hline r_ftse & -2.862000 & -60.15540 & 0.0001 \\
\hline r_kompas100 & -2.862424 & -31.23000 & 0.0000 \\
\hline r_pefindo_25 & -2.862626 & -45.97859 & 0.0001 \\
\hline r_lq45 & -2.862010 & -59.74620 & 0.0001 \\
\hline \multicolumn{4}{|c|}{} \\
\hline
\end{tabular}

\begin{tabular}{|c|c|c|c|c|}
\hline \multicolumn{5}{|c|}{ Tabel 10. Hasil Markov Switching Regime Indeks Tambahan } \\
\hline Parameter & Koefisien & Std. Error & z-Statistik & Prob. \\
\hline \multicolumn{5}{|c|}{ Regime 1 } \\
\hline C & 0.001558 & 0.000236 & 6.596980 & 0.0000 \\
\hline
\end{tabular}

\begin{tabular}{|c|c|c|c|c|}
\hline \multicolumn{5}{|c|}{ Regime 2} \\
\hline C & 0.002075 & 0.000935 & 2.218179 & 0.02635 \\
\hline \multicolumn{5}{|c|}{ Common } \\
\hline LOG(SIGMA) & -4.226495 & 0.012022 & -351.5679 & 0.0000 \\
\hline \multicolumn{5}{|c|}{ r_kompas100 } \\
\hline \multicolumn{5}{|c|}{ Regime 1} \\
\hline C & -0.002631 & 0.001365 & -1.928281 & 0.0538 \\
\hline LOG(SIGMA) & -3.562084 & 0.048441 & -73.53440 & 0.0000 \\
\hline \multicolumn{5}{|c|}{ Regime 2} \\
\hline C & 0.001162 & 0.000242 & 4.799436 & 0.0000 \\
\hline LOG(SIGMA) & -4.696267 & 0.030774 & -152.6055 & 0.0000 \\
\hline \multicolumn{5}{|c|}{ r_pefindo_25 } \\
\hline \multicolumn{5}{|c|}{ Regime 1} \\
\hline C & -0.001251 & 0.001345 & -0.930040 & 0.3524 \\
\hline LOG(SIGMA) & -3.764557 & 0.060187 & -62.54789 & 0.0000 \\
\hline \multicolumn{5}{|c|}{ Regime 2} \\
\hline C & 0.000716 & 0.000241 & 2.964709 & 0.0030 \\
\hline LOG(SIGMA) & -4.620429 & 0.025855 & -178.7044 & 0.0000 \\
\hline \multicolumn{5}{|c|}{ r_lo45 } \\
\hline \multicolumn{5}{|c|}{ Regime 1} \\
\hline C & 0.001293 & 0.000871 & -1.484140 & 0.1378 \\
\hline LOG(SIGMA) & -3.642962 & 0.033015 & -110.3420 & 0.0000 \\
\hline \multicolumn{5}{|c|}{ Regime 2} \\
\hline C & 0.001321 & 0.000203 & 6.520274 & 0.0000 \\
\hline LOG(SIGMA) & -4.567370 & 0.023200 & -196.857 & 0.0000 \\
\hline \multicolumn{5}{|c|}{ Sumber: Diolah Sendir } \\
\hline
\end{tabular}

\begin{tabular}{|c|c|c|c|c|}
\hline \multicolumn{5}{|c|}{ Tabel 11. Transition Matrix Parameters Indeks Tambahan } \\
\hline Parameter & Koefisien & Std. Error & t-Statistik & Prob. \\
\hline P11-C & 2.309833 & 0.000203 & 11.36860 & 0.0000 \\
\hline P21-C & -3.516699 & 0.023200 & -17.42255 & 0.0000 \\
\hline \multicolumn{5}{|c|}{ r_kompas100 } \\
\hline P11-C & 2.525692 & 0.258046 & 9.787764 & 0.0000 \\
\hline P21-C & -4.688077 & 0.026638 & -15.34319 & 0.0000 \\
\hline \multicolumn{5}{|c|}{ r_pefindo_25 } \\
\hline P11-C & 2.278152 & 0.297826 & 7.649281 & 0.0000 \\
\hline P21-C & -4.043665 & 0.305276 & -13.24594 & 0.0000 \\
\hline \multicolumn{5}{|c|}{ r_lq45 } \\
\hline P11-C & 2.309833 & 0.203177 & 11.36860 & 0.0000 \\
\hline P21-C & -3.516699 & 0.201848 & -17.42255 & 0.0000 \\
\hline & & & Sumber: Diolah Sendiri \\
\hline
\end{tabular}

\begin{tabular}{|c|c|c|}
\hline \multicolumn{3}{|c|}{$\begin{array}{c}\text { Tabel 12. Probabilitas Transisi dan } \\
\text { Durasi Harapan Indeks Tambahan }\end{array}$} \\
\hline \multicolumn{3}{|c|}{ r_ftse } \\
\hline Probabilitas Transisi & 1 & $\mathbf{2}$ \\
\hline 1 & 0.988508 & 0.011492 \\
\hline 2 & 0.704430 & 0.295570 \\
\hline Durasi Harapan & 1 & $\mathbf{2}$ \\
\hline
\end{tabular}


JURNAL MADANI: Ilmu Pengetahuan, Teknologi, dan Humaniora, Vol. 1, No. 2, September 2018: 417 - 429

\begin{tabular}{|c|c|c|}
\hline & 87.01860 & 1.419588 \\
\hline \multicolumn{3}{|c|}{ r_kompas100 } \\
\hline Probabilitas Transisi & 1 & 2 \\
\hline 1 & 0.925923 & 0.074077 \\
\hline 2 & 0.024423 & 0.975577 \\
\hline \multirow[t]{2}{*}{ Durasi Harapan } & 1 & 2 \\
\hline & 13.49955 & 40.94546 \\
\hline \multicolumn{3}{|c|}{ r_pefindo_25 } \\
\hline Probabilitas Transisi & 1 & 2 \\
\hline 1 & 0.907051 & 0.092949 \\
\hline 2 & 0.017231 & 0.982769 \\
\hline \multirow{2}{*}{ Durasi Harapan } & 1 & 2 \\
\hline & 10.75863 & 58.03497 \\
\hline \multicolumn{3}{|c|}{ r_la45 } \\
\hline Probabilitas Transisi & 1 & 2 \\
\hline 1 & 0.909688 & 0.090312 \\
\hline 2 & 0.028841 & 0.971159 \\
\hline \multirow[t]{2}{*}{ Durasi Harapan } & 1 & 2 \\
\hline & 11.07274 & 34.67310 \\
\hline \multicolumn{3}{|c|}{ Sumber: Diolah Sendiri } \\
\hline
\end{tabular}

\begin{tabular}{|l|c|c|c|}
\hline \multicolumn{5}{|c|}{ Tabel 13. ADF Unit Root Test Indeks Lainnya } \\
\hline \multicolumn{1}{|c|}{ Indeks Tambahan } & $\begin{array}{c}\text { Parameters } \\
\text { ADF Test 5\% }\end{array}$ & t-Statistik & Prob.* \\
\hline return_idx30 & -2.863232 & -25.58560 & 0.0000 \\
\hline r_banking & -2.863429 & -33.71600 & 0.0000 \\
\hline r_bisnis27 & -2.862585 & -30.86435 & 0.0000 \\
\hline r_islamic & -2.862010 & -61.46539 & 0.0000 \\
\hline r_main_board & -2.862071 & -37.65376 & 0.0000 \\
\hline r_shariah & -2.862984 & -16.88721 & 0.0000 \\
\hline r_srikehati & -2.862635 & -31.25640 & 0.0000 \\
\hline r_investor33 & -2.864092 & -30.73957 & 0.0000 \\
\hline r_mnc36 & -2.863774 & -22.05813 & 0.0000 \\
\hline r_sminfra18 & -2.863517 & -23.79521 & 0.0000 \\
\hline \multicolumn{4}{|c|}{ Sumber: Diolah Sendiri } \\
\hline
\end{tabular}

\begin{tabular}{|c|c|c|c|c|}
\hline \multicolumn{5}{|c|}{ Tabel 14. Hasil Markov Switching Regime Indeks Lainnya } \\
\hline Parameter & Koefisien & Std. Error & z-Statistik & Prob. \\
return_idx30 \\
\hline \multicolumn{5}{|c|}{ Regime 1 } \\
\hline C & -0.00108 & 0.000999 & -1.009719 & 0.3126 \\
\hline LOG(SIGMA) & -3.930768 & 0.046493 & -84.54498 & 0.0000 \\
\hline \multicolumn{5}{|c|}{ Regime 2 } \\
\hline C & 0.000827 & 0.000267 & 3.099133 & 0.0019 \\
\hline LOG(SIGMA) & -4.815624 & 0.035291 & -136.4567 & 0.0000 \\
\hline \multicolumn{5}{|c|}{ Reganking } \\
\hline \multicolumn{5}{|c|}{ Regime 2 1 } \\
\hline C & -0.000911 & 0.001123 & -0.810901 & 0.4174 \\
\hline LOG(SIGMA) & -3.822228 & 0.044576 & -85.74670 & 0.0000 \\
\hline \multicolumn{5}{|c|}{} \\
\hline
\end{tabular}

\begin{tabular}{|c|c|c|c|c|}
\hline C & 0.001204 & 0.000312 & 3.856012 & 0.0001 \\
\hline LOG(SIGMA) & -4.729617 & 0.033619 & -140.6834 & 0.0000 \\
\hline \multicolumn{5}{|c|}{ r_bisnis27 } \\
\hline \multicolumn{5}{|c|}{ Regime 1} \\
\hline$C$ & 0.001027 & 0.000247 & 4.154220 & 0.0000 \\
\hline LOG(SIGMA) & -4.675260 & 0.030240 & -156.6045 & 0.0000 \\
\hline \multicolumn{5}{|c|}{ Regime 2} \\
\hline$C$ & -0.000132 & 0.000901 & -0.145970 & 0.8839 \\
\hline LOG(SIGMA) & -3.826434 & 0.039469 & -96.94737 & 0.0000 \\
\hline \multicolumn{5}{|c|}{ r_islamic } \\
\hline \multicolumn{5}{|c|}{ Regime 1} \\
\hline C & -001087 & 0.000229 & 4.739414 & 0.0000 \\
\hline LOG(SIGMA) & -4.550171 & 0.029097 & -156.3767 & 0.0000 \\
\hline \multicolumn{5}{|c|}{ Regime 2} \\
\hline C & -0.000843 & 0.001058 & -0.796945 & 0.4255 \\
\hline LOG(SIGMA) & -3.550171 & 0.041925 & -85.29729 & 0.0000 \\
\hline \multicolumn{5}{|c|}{ r_main_board } \\
\hline \multicolumn{5}{|c|}{ Regime 1} \\
\hline C & 0.001261 & 0.000186 & 6.776773 & 0.0000 \\
\hline LOG(SIGMA) & -4.697235 & 0.024159 & -194.4279 & 0.0000 \\
\hline \multicolumn{5}{|c|}{ Regime 2} \\
\hline$C$ & -0.001017 & 0.000822 & -1.238051 & 0.2157 \\
\hline LOG(SIGMA) & -3.747589 & 0.034591 & -108.3413 & 0.0000 \\
\hline \multicolumn{5}{|c|}{ r_shariah } \\
\hline \multicolumn{5}{|c|}{ Regime 1} \\
\hline$C$ & -0.002006 & 0.001179 & -1.701463 & 0.0007 \\
\hline LOG(SIGMA) & -3.942745 & 0.062774 & -62.80829 & 0.0000 \\
\hline \multicolumn{5}{|c|}{ Regime 2} \\
\hline C & 0.000741 & 0.000219 & 3.387756 & 0.0007 \\
\hline LOG(SIGMA) & -4.863968 & 0.031587 & -153.9840 & 0.0000 \\
\hline \multicolumn{5}{|c|}{ r_srikehati } \\
\hline \multicolumn{5}{|c|}{ Regime 1} \\
\hline$C$ & 0.001040 & 0.000244 & 4.269485 & 0.0000 \\
\hline LOG(SIGMA) & -4.714125 & 0.028371 & -166.1621 & 0.0000 \\
\hline \multicolumn{5}{|c|}{ Regime 2} \\
\hline$C$ & -0.000670 & 0.000881 & -0.760191 & 0.4471 \\
\hline LOG(SIGMA) & -3.883684 & 0.40493 & -95.90927 & 0.0000 \\
\hline \multicolumn{5}{|c|}{ r_investor33 } \\
\hline \multicolumn{5}{|c|}{ Regime 1} \\
\hline C & 0.000602 & 0.000301 & 1.997902 & 0.0457 \\
\hline LOG(SIGMA) & -4.877831 & 0.035444 & -137.6195 & 0.0000 \\
\hline \multicolumn{5}{|c|}{ Regime 2} \\
\hline C & -0.000721 & 0.001172 & -0.615395 & 0.5383 \\
\hline LOG(SIGMA) & -4.010004 & 0.058442 & -68.61538 & 0.0000 \\
\hline \multicolumn{5}{|c|}{ r_mnc36 } \\
\hline \multicolumn{5}{|c|}{ Regime 1} \\
\hline C & 0.000711 & 0.000287 & 2.477053 & 0.0132 \\
\hline LOG(SIGMA) & -4.891264 & 0.037439 & -130.6474 & 0.0000 \\
\hline
\end{tabular}


JURNAL MADANI: Ilmu Pengetahuan, Teknologi, dan Humaniora, Vol. 1, No. 2, September 2018: 417 - 429

\begin{tabular}{|c|c|c|c|c|}
\hline \multicolumn{5}{|c|}{ Regime 2 } \\
\hline C & -0.0000469 & 0.001018 & -0.046101 & 0.9632 \\
\hline LOG(SIGMA) & -4.003591 & 0.053217 & -75.23111 & 0.0000 \\
\hline \multicolumn{5}{|c|}{ r_sminfira18 } \\
\hline \multicolumn{5}{|c|}{ Regime 1 } \\
\hline C & 0.000296 & 0.000332 & -0.893284 & 0.3717 \\
\hline LOG(SIGMA) & -4.783653 & 0.042212 & -113.3232 & 0.0000 \\
\hline \multicolumn{5}{|c|}{ Regime 2 } \\
\hline C & -0.000259 & 0.000898 & -0.288865 & 0.7727 \\
\hline LOG(SIGMA) & -3.995683 & 0.049177 & -81.25114 & 0.0000 \\
\hline & \multicolumn{5}{|c|}{ Sumber: Diolah Sendiri } \\
\hline
\end{tabular}

\begin{tabular}{|c|c|c|c|c|}
\hline \multicolumn{5}{|c|}{ Tabel 15. Transition Matrix Parameters Indeks Lainnya } \\
\hline Parameter & Koefisien & Std. Error & t-Statistik & Prob. \\
\hline \multicolumn{5}{|c|}{ Return_idx30 } \\
\hline P11-C & 2.484122 & 0.335720 & 3.099113 & 0.0000 \\
\hline P21-C & -3.461312 & 0.317586 & -10.89882 & 0.0000 \\
\hline \multicolumn{5}{|c|}{ r_banking } \\
\hline P11-C & 2.452762 & 0.319085 & 7.686855 & 0.0000 \\
\hline P21-C & -3.348224 & 0.303149 & -11.04482 & 0.0000 \\
\hline \multicolumn{5}{|c|}{ r_bisnis27 } \\
\hline P11-C & 3.841818 & 0.310969 & 12.35434 & 0.0000 \\
\hline P21-C & -2.810815 & 0.293784 & -9.567616 & 0.0000 \\
\hline \multicolumn{5}{|c|}{ r_islamic } \\
\hline P11-C & 3.595913 & 0.204003 & 17.62680 & 0.0000 \\
\hline P21-C & -2.471472 & 0.215675 & -11.45924 & 0.0000 \\
\hline \multicolumn{5}{|c|}{ r_main_board } \\
\hline P11-C & 3.566048 & 0.215475 & 16.54973 & 0.0000 \\
\hline P21-C & -2.345641 & 0.219311 & -10.69467 & 0.0000 \\
\hline \multicolumn{5}{|c|}{ r_shariah } \\
\hline P11-C & 2.523439 & 0.328243 & 7.687723 & 0.0000 \\
\hline P21-C & -4.149278 & 0.357422 & -11.60889 & 0.0000 \\
\hline \multicolumn{5}{|c|}{ r_srikehati } \\
\hline P11-C & 3.593549 & 0.276819 & 12.98158 & 0.0000 \\
\hline P21-C & -2.561257 & 0.288361 & -8.882133 & 0.0000 \\
\hline \multicolumn{5}{|c|}{ r_investor33 } \\
\hline P11-C & 3.311514 & 0.324768 & 10.19654 & 0.0000 \\
\hline P21-C & -2.187900 & 0.370570 & -5.904147 & 0.0000 \\
\hline \multicolumn{5}{|c|}{ r_mnc36 } \\
\hline P11-C & 3.194917 & 0.295642 & 10.80671 & 0.0000 \\
\hline P21-C & -2.291744 & 0.344295 & -6.656336 & 0.0000 \\
\hline \multicolumn{5}{|c|}{ r_sminfiral8 } \\
\hline P11-C & 2.961573 & 0.294185 & 10.06703 & 0.0000 \\
\hline P21-C & -2.317341 & 0.332738 & -6.964459 & 0.0000 \\
\hline \multicolumn{5}{|c|}{ Sumber: Diolah Sendir } \\
\hline
\end{tabular}

\begin{tabular}{|c|c|c|}
\hline \multicolumn{2}{|c|}{ Tabel 12. Probabilitas Transisi dan Durasi Harapan Indek } & Return_idx30 \\
\hline Probabilitas Transisi & 1 & 2 \\
\hline 1 & 0.923021 & 0.076979 \\
\hline 2 & 0.030433 & 0.969567 \\
\hline Durasi Harapan & 1 & 2 \\
\hline & 12.99059 & 32.85875 \\
\hline \multicolumn{3}{|c|}{ r_banking } \\
\hline Probabilitas Transisi & 1 & 2 \\
\hline 1 & 0.920763 & 0.079237 \\
\hline 2 & 0.033953 & 0.966047 \\
\hline Durasi Harapan & 1 & 2 \\
\hline & 12.62039 & 29.45216 \\
\hline \multicolumn{3}{|c|}{ r_bisnis27 } \\
\hline Probabilitas Transisi & 1 & 2 \\
\hline 1 & 0.978996 & 0.021004 \\
\hline 2 & 0.056743 & 0.943257 \\
\hline Durasi Harapan & 1 & 2 \\
\hline & 47.61016 & 17.62346 \\
\hline \multicolumn{3}{|c|}{ r_islamic } \\
\hline Probabilitas Transisi & 1 & 2 \\
\hline 1 & 0.973297 & 0.026703 \\
\hline 2 & 0.077882 & 0.922118 \\
\hline Durasi Harapan & 1 & 2 \\
\hline & 37.44895 & 12.83987 \\
\hline \multicolumn{3}{|c|}{ r_main_board } \\
\hline Probabilitas Transisi & 1 & 2 \\
\hline 1 & 0.972510 & 0.027490 \\
\hline 2 & 0.087427 & 0.912573 \\
\hline Durasi Harapan & 1 & 2 \\
\hline & 36.37653 & 11.43808 \\
\hline \multicolumn{3}{|c|}{ r_shariah } \\
\hline Probabilitas Transisi & 1 & 2 \\
\hline 1 & 0.925769 & 0.074231 \\
\hline 2 & 0.015531 & 0.984469 \\
\hline Durasi Harapan & 1 & 2 \\
\hline & 13.47141 & 64.38822 \\
\hline \multicolumn{3}{|c|}{ r_srikehati } \\
\hline Probabilitas Transisi & 1 & 2 \\
\hline 1 & 0.973235 & 0.026765 \\
\hline 2 & 0.071674 & 0.928236 \\
\hline Durasi Harapan & 1 & 2 \\
\hline & 37.36290 & 13.95209 \\
\hline \multicolumn{3}{|c|}{ r_investor33 } \\
\hline Probabilitas Transisi & 1 & 2 \\
\hline 1 & 0.964822 & 0.035178 \\
\hline 2 & 0.100842 & 0.899158 \\
\hline Durasi Harapan & 1 & 2 \\
\hline
\end{tabular}




\begin{tabular}{|c|c|c|}
\hline & 28.42662 & 9.916469 \\
\hline \multicolumn{3}{|c|}{ r_mnc36 } \\
\hline Probabilitas Transisi & 1 & 2 \\
\hline 1 & 0.960643 & 0.039357 \\
\hline 2 & 0.091809 & 0.908191 \\
\hline \multirow[t]{2}{*}{ Durasi Harapan } & 1 & 2 \\
\hline & 25.40815 & 10.89217 \\
\hline \multicolumn{3}{|c|}{ r_sminfra18 } \\
\hline Probabilitas Transisi & 1 & 2 \\
\hline 1 & 0.950808 & 0.049192 \\
\hline 2 & 0.089697 & 0.910303 \\
\hline \multirow[t]{2}{*}{ Durasi Harapan } & 1 & 2 \\
\hline & 20.32835 & 11.14866 \\
\hline \multicolumn{3}{|c|}{ Sumber: Diolah Sendiri } \\
\hline
\end{tabular}

\section{Pembahasan \\ Indeks Utama}

Indeks utama di regime 1 tidak memiliki signifikan pada intercept sebesar $-0.1501 \%$ dan memiliki volatilitas -3.799 secara signifikan dan regime 2 memiliki signifikan dalam mean sebesar $0.1371 \%$ dan volatilitas.sebesar -4.745649. Ini memiliki arti $r \_j k s e$ tidak stabil. Probabilitas transisi memiliki probabilitas yang tinggi pada rezim sesungguhnya. pada $\left(\mathrm{S}_{\mathrm{t}}=1 \mid \mathrm{S}_{\mathrm{t}-1}=1\right)$ sebesar 0.902428 dan $\left(\mathrm{S}_{\mathrm{t}}=2 \mid \mathrm{S}_{\mathrm{t}-1}=2\right)$ sebesar 0.970231 . Peluang perubahan transisi dari regime 1 ke 2 dan 2 ke 1 adalah sebesar 9.7572\% dan $2.9769 \%$. Durasi harapan pada regime 1178.5060 hari dan 1.00012 hari. Ini memiliki arti bahwa $\mathrm{r}_{-} j \mathrm{kse}$ akan mengalami bearish tidak nyata atau berfluktuasi tanpa trend selama 178.5060 hari dan positif (bullish) selama 1 hari.

\section{Indeks Sektor-sektor Primer}

Indeks sektor-sektor primer adalah return agriculture, r_basic_industry, r_consumer_ industry, r_development_board, r_finance, r_infrastructure, r_manufacture, r_mining, r_miscellaneous_indu, r_property, dan r_trade.

Return_agriculture pada regime 1 memiliki intercept $0.0065 \%$ dan volatilitas sebesar -4.489978 dan pada regime 2 memiliki intercept $0.2075 \%$ dan volatilitas -3.402745 . Regime 1 memiliki $\rho>0.05$ dan Regime 2 memiliki $\rho<0.05$ yang memiliki arti trend bearish pada regime 1 tidak substansial. R_basic_industry pada regime 1 memiliki intercept $-0.1551 \%$ dan volatilitas -3.620394 dan pada regime 2 memiliki intercept
$0.1298 \%$ dan volatilitas -4.489792 . r_basic industry pada regime $1 \rho>0.05$ dan regime 2 $\rho<0.05$. Trend bearish pada regime satu tidak substansial. R_consumer_industry pada regime 1 memiliki mean $5.585112 \%$ dan volatilitas -1.111282 sedangkan pada regime 2 memiliki intercept $0.0847 \%$ dan volatilitas -4.341761 . $\mathrm{r}_{-}$ consumer_industry pada regime $1 \rho>0.05$ dan regime $2 \rho<0.05$. r_consumer_industry tidak stabil. r_development_board pada regime 1 dan 2 memiliki mean dan volatilitas sebesar $0.1055 \%$ dan -4.996596 , dan $0.0973 \%$ dan -4.935654. r_development_board pada regime $1 \rho<0.05$ dan regime $2 \rho<0.05$ artinya stabil. $\mathrm{R}_{\text {_ }}$ finance pada regime 1 dan 2 memiliki mean dan volatilitas sebesar $0.1045 \%$ dan -4.676198 , dan $0.0621 \%$ dan -3.797280 . r_finance pada regime $1 \rho<0.05$ dan regime $2 \rho>0.05$ artinya uptrend pada regime 2 pada indeks finance tidak nyata tetapi bearish lebih nyata maka r_finance terjadi volatile atau tidak stabil. $\mathrm{R}$ _infrastructure pada regime 1 dan 2 memiliki intercept dan volatilitas sebesar $0.6048 \%$ dan $-2.904655,0.0841 \%$ dan -4.076356.r_infrastructure pada regime $1 \rho>0.05$ dan regime $2 \rho<0.05$ artinya tidak stabil. $R_{\text {_ }}$ manufacture pada regime 1 dan 2 memiliki mean dan volatilitas sebesar $0.1024 \%$ dan -4.371601 , 2.2959\% dan -1.552219. r_manufacture pada regime $1 \rho<0.05$ dan regime $2 \rho>0.05$ artinya tidak stabil. R_mining pada regime 1 dan 2 memiliki intercept dan volatilitas sebesar $0.2264 \%$ dan $-3.328309,0.0421 \%$ dan -4.377384 . r_mining pada regime $1 \rho<0.05$ dan regime 2 $\rho>0.05$ artinya tidak stabil. R_miscellaneous_ indu pada regime 1 dan 2 memiliki mean dan volatilitas $0.0455 \%$ dan $-4.274376,0.1915 \%$ dan -3.424537. r_miscellaneous_indu pada regime $1 \rho<0.05$ dan regime $2 \rho<0.05$ artinya stabil. R_properti pada regime 1 dan 2 memiliki mean dan volatilitas $0.0626 \%$ dan $-3.646611,0.0768 \%$ dan -4.601555. r_property pada regime 1 dan 2 memiliki $\rho$ sebesar $>0.05$ dan $<0.05$ artinya r_property tidak stabil atau berfluktuasi. R_ trade pada regime 1 dan 2 memiliki mean dan volatilitas $0.1068 \%$ dan $-4.694064,-0.1515 \%$ dan -3.774536. $r$ _trade pada regime $1 \rho<0.05$ dan regime $2 \rho>0.05$ artinya regime 1 tidak stabil.

Pada regime 1 dan 2 return_agriculture peluang kondisi akan bertahan setelah mencapai 95.7343\% dan 90.735\%, akan berlangsung selama 23.44297 hari dan 10.79328 hari dan perubahan probabilitas pindah dari regime 1 ke 
2 dan regime 2 ke 1 sebesar $4.2657 \%$ dan $9.265 \%$. r_basic_industry berada pada regime 1 dan 2 akan bertahan $88.7732 \%$ dan $96.9449 \%$ selama 8.907267 hari dan 32.73221 hari. Probabilitas perpindahan dari regime 1 dan 2 lebih besar dari regime 2 ke 1 sebesar $11.2268 \%$ dan 3.0551\%. r_ consumer_industry dapat bertahan pada regime satu dan dua setelah mencapai $46.2601 \%$ dan $99.2656 \%$ selama 1.860814 hari dan 136.1571 hari dengan peluang transisi dari regime satu ke dua dan regime dua ke satu sebesar $53.7399 \%$ dan 0.7344\%. r_development_board akan bertahan di regime satu dan dua setelah mencapai kondisi 97.6494\% dan $95.1636 \%$ selama 42.5436 hari dan 20.67645 hari dengan peluang transisi dari regime satu ke dua dan dua ke satu sebesar $2.3506 \%$ dan $4.8364 \%$. r_finance dapat bertahan di regime satu dan dua setelah mencapai kondisi 95.9672\% dan $93.5776 \%$ selama 24.79679 hari dan 15.57058 hari dengan peluang transisi dari regime satu ke dua dan dua ke satu sebesar $4.0328 \%$ dan $6.4224 \%$. r_infrastructure dapat bertahan di regime satu dan dua setelah mencapai kondisi $97.0151 \%$ dan $78.4856 \%$ selama 33.50238 hari dan 4.648051 hari dengan peluang transisi dari regime satu ke dua dan dua ke satu sebesar $2.9849 \%$ dan $21.5144 \%$. r_ manufacture dapat bertahan di regime satu dan dua setelah mencapai kondisi $99.2503 \%$ dan $50.0844 \%$ selama 133.3786 hari dan 2.003382 hari dengan peluang transisi dari regime satu ke dua dan dua ke satu sebesar 0.7497\% dan $49.9156 \%$. r_mining dapat bertahan di regime satu dan dua setelah mencapai kondisi 94.7349\% dan $98.2309 \%$ selama 18.99304 hari dan 56.52435 hari dengan peluang transisi dari regime satu ke dua dan dua ke satu sebesar $5.2651 \%$ dan $1.79691 \%$. r_miscellaneous_indu dapat bertahan di regime satu dan dua setelah mencapai kondisi $96.8082 \%$ dan $88.4056 \%$ selama 31.32980 hari dan 8.624824 hari dengan peluang transisi dari regime satu ke dua dan dua ke satu sebesar 3.1918\% dan 11.5944\%. r_property dapat bertahan di regime satu dan dua setelah mencapai kondisi $89.9857 \%$ dan 96.9024\% selama 9.985765 hari dan 32.28285 hari dengan peluang transisi dari regime satu ke dua dan dua ke satu sebesar $10.0143 \%$ dan 3.0976\%. r_trade dapat bertahan di regime satu dan dua setelah mencapai kondisi 98.0115\% dan 92.4471\% selama 50.28933 hari dan 13.23991 hari dengan peluang transisi dari regime satu ke dua dan dua ke satu sebesar $1.9885 \%$ dan 7.5529\%.

\section{Indeks Tambahan}

R_ftse pada regime 1 dan 2 memiliki mean dan signifikansi sebesar $0.1558 \%$ dan $0.2075 \%$ serta $\rho<0.05$ dikedua regime artinya $r_{-}$ftse stabil. R_kompas100 pada regime 1 dan 2 memiliki mean, dan signifikansi sebesar $-0.2631 \%$ dan -3.562084, 0.1162 dan -4.696267 , dan $\rho>0.05$ dan $\rho<0.05$. r_kompas 100 tidak stabil. r_pefindo25 pada regime 1 dan 2 memiliki mean,volatilitas, dan signifikansi sebesar $-0.1251 \%$ dan $-3.764557,0.0716 \%$ dan -4.620429 , dan $\rho>0.05$ dan $\rho<0.05$. r_pefindo tidak stabil. r_lq45 pada regime 1 dan 2 memiliki mean, volatilitas, dan signifikansi sebesar $0.1293 \%$ dan -3.642962 , $0.1321 \%$ dan -4.567370 , dan $\rho<0.05$ dan $\rho<0.05$. r_lq45 artinya stabil.

r_ftse dapat bertahan di regime satu dan dua setelah mencapai kondisi $98.8508 \%$ dan $29.5570 \%$ selama 87.01860 hari dan 1.419588 hari dengan peluang transisi dari regime satu ke dua dan dua ke satu sebesar $1.1492 \%$ dan $70.443 \%$. r_kompas100 dapat bertahan di regime satu dan dua setelah mencapai kondisi 92.5923\% dan $97.4077 \%$ selama 13.49955 hari dan 40.94546 hari dengan peluang transisi dari regime satu ke dua dan dua ke satu sebesar $7.4077 \%$ dan $2.4423 \%$. r_pefindo25 dapat bertahan di regime satu dan dua setelah mencapai kondisi $90.7051 \%$ dan $98.2769 \%$ selama 10.75863 hari dan 58.03497 hari dengan peluang transisi dari regime satu ke dua dan dua ke satu sebesar 9.2949\% dan 1.75863\%.r_lq45 dapat bertahan di regime satu dan dua setelah mencapai kondisi $90.9688 \%$ dan $97.1159 \%$ selama 11.07274 hari dan 34.67310 hari dengan peluang transisi dari regime satu ke dua dan dua ke satu sebesar $9.0312 \%$ dan $2.8841 \%$.

\section{Indeks Lainnya}

Return_idx30 pada regime 1 dan 2 memiliki mean, volatilitas, dan signifikansi sebesar $-0.108 \%$ dan $-3.930768,0.0827 \%$ dan -4.815624 , dan $\rho<0.05$ dan $\rho<0.05$. return_idx30 stabil. r_ banking pada regime 1 dan 2 memiliki mean, volatilitas, dan signifikansi sebesar -0.0911\% dan $-3.822225,0.1204 \%$ dan -4.729654 , dan $\rho>0.05$ dan $\rho<0.05$. r_banking memiliki ketidakstabilan. R_bisnis27 pada regime 1 dan 2 memiliki mean, volatilitas, dan signifikansi 
sebesar $0.1027 \%$ dan $-4.675260,-0.0132 \%$ dan $-3.826434, \rho<0.05$ dan $\rho>0.05$. r_bisnis 27

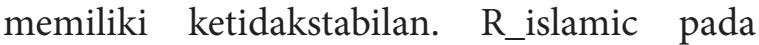
regime 1 dan 2 memiliki mean, volatilitas, dan signifikansi sebesar $-0.1087 \%$ dan -4.550171 , $-0.0843 \%$ dan $-3.550171, \rho<0.05$ dan $\rho>0.05$. r_islamic memiliki ketidaksabilan. R_main_ board pada regime 1 dan 2 memiliki mean, volatilitas, dan signifikansi sebesar -\#0.1261\% dan -4.697235, ---0.1017 dan -3.747589, $\rho<0.05$ dan $\rho>0.05$. r_main_board memiliki ketidakstabilan. R_shariah pada regime 1 dan 2 memiliki mean, volatilitas, dan signifikansi sebesar $-0.2006 \%$ dan $-3.942745, \quad 0.0741 \%$ dan -4.863968 , dan $\rho<0.05$ dan $\rho<0.05$. $r_{-}$ shariah memiliki kestabilan. R_srikehati pada regime 1 dan 2 memiliki mean, volatilitas, dan signifikansi sebesar 0.001040 dan -4.714125 , $-0.067 \%$ dan $-3.883684, \rho<0.05$ dan $\rho>0.05$. r_srikehati memiliki ketidakstabilan. R_ investor33 pada regime 1 dan 2 memiliki mean, volatility, dan signifikansi sebesar 0.0602 dan -4.877831, - 0.0721 dan -4.010004, dan $\rho<0.05$ dan $\rho>0.05$. r_investor33 memiliki ketidakstabilan. R_mnc36 pada regime 1 dan 2 memiliki mean, volatilitas dan signifikansi sebesar $0.0711 \%$ dan $-4.891264,-0.00469 \%$ dan -4.003591 , dan $\rho<0.05$ dan $\rho>0.05$. r_mnc36 memiliki ketidakstabilan. R_sminfra18 pada regime 1 dan 2 memiliki mean, volatilitas dan signifikansi sebesar $0.0296 \%$ dan -4.782653 , -0.0259 dan -3.995683 , dan $\rho>0.05$ dan $\rho>0.05$. r_sminfra memiliki ketidakstabilan.

Return_idx30 dapat bertahan di regime satu dan dua setelah mencapai kondisi 92.3021\% dan $96.9567 \%$ selama 12.99059 hari dan 32.85875 hari dengan peluang transisi dari regime satu ke dua dan dua ke satu sebesar $7.6979 \%$ dan 3.0433\%. r_banking dapat bertahan di regime satu dan dua setelah mencapai kondisi $92.0763 \%$ dan $96.6047 \%$ selama 12.62039 hari dan 29.45216 hari dengan peluang transisi dari regime satu ke dua dan dua ke satu sebesar $7.9237 \%$ dan 3.3953\%. r_bisnis27 dapat bertahan di regime satu dan dua setelah mencapai kondisi $97.8996 \%$ dan 94.3257\% selama 47.61016 hari dan 17.62346 hari dengan peluang transisi dari regime satu ke dua dan dua ke satu sebesar 2.1004\% dan 9.43257\%. r_islamic dapat bertahan di regime satu dan dua setelah mencapai kondisi 97.3297\% dan $92.2118 \%$ selama 37.44895 hari dan 12.83987 hari dengan peluang transisi dari regime satu ke dua dan dua ke satu sebesar $2.6703 \%$ dan $7.7882 \%$. r_main_board dapat bertahan di regime satu dan dua setelah mencapai kondisi $97.2510 \%$ dan $91.2573 \%$ selama 36.37653 hari dan 11.43808 hari dengan peluang transisi dari regime satu ke dua dan dua ke satu sebesar $2.7490 \%$ dan $8.7427 \%$. r_shariah dapat bertahan di regime satu dan dua setelah mencapai kondisi $92.5769 \%$ dan $98.4469 \%$ selama 13.47141 hari dan 64.38822 hari dengan peluang transisi dari regime satu ke dua dan dua ke satu sebesar $7.4231 \%$ dan $1.5531 \%$. r_srikehati dapat bertahan di regime satu dan dua setelah mencapai kondisi $97.3235 \%$ dan $92.8236 \%$ selama 37.36290 hari dan 13.95209 hari dengan peluang transisi dari regime satu ke dua dan dua ke satu sebesar $2.6765 \%$ dan 7.1674\%. r_investor33 dapat bertahan di regime satu dan dua setelah mencapai kondisi $96.4822 \%$ dan $89.9158 \%$ selama 28.42662 hari dan 9.916469 hari dengan peluang transisi dari regime satu ke dua dan dua ke satu sebesar $3.5178 \%$ dan $10.0842 \%$. r_mnc36 dapat bertahan di regime satu dan dua setelah mencapai kondisi $96.0643 \%$ dan $90.8191 \%$ selama 25.40815 hari dan 10.89217 hari dengan peluang transisi dari regime satu ke dua dan dua ke satu sebesar 3.9357\% dan 9.1809\%. r_ sminfra18 dapat bertahan di regime satu dan dua setelah mencapai kondisi $95.0808 \%$ dan 91.0303\% selama 20.32835 hari dan 11.14866 hari dengan peluang transisi dari regime satu ke dua dan dua ke satu sebesar $4.9192 \%$ dan $8.9697 \%$

\section{KESIMPULAN DAN SARAN Kesimpulan}

Berdasarkan pendekatan Markov Switching Regression indeks-indeks yang ada di Indonesia tidak stabil kecuali indeks development board, indeks miscellaneous industry, indeks ftse Indonesia, LQ-45, indeks 30 saham, dan indeks shariah.

\section{Saran}

Perlu diwaspadai untuk berinvestasi di pasar modal Indonesia selain indeks development board, indeks miscellaneous industry, indeks $\mathrm{ftse}$ Indonesia, LQ-45, indeks 30 saham, dan indeks shariah karena tidak mempunyai trend 
yang nyata atau pergerakannya hanya fluktuatif atau bersifat sementara.

\section{DAFTAR PUSTAKA}

(n.d.). Retrieved July 22, 2018, from https:// www.investing.com/indices/ftseindonesia-historical-data

(n.d.). Retrieved July 22, 2018, from https:// www.investing.com/indices/kompas-100historical-data

(n.d.). Retrieved July 22, 2018, from https:// www.investing.com/indices/jakarta-lq45historical-data

(n.d.). Retrieved July 22, 2018, from https:// www.investing.com/pefindo-25-historicaldata

(n.d.). Retrieved July 22, 2018, from https:// www. investing.com/indices/idxagriculture-historical-data

(n.d.). Retrieved July 22, 2018, from https:// www.investing.com/indices/idx-basicindustry-historical-data

(n.d.). Retrieved July 22, 2018, from https//www. investing.com/indices/idx-consumerindustry-historical-data

(n.d.). Retrieved July 22, 2018, from https:// www.investing.com/indices/idxdevelopment-historical-data

(n.d.). Retrieved July 22, 2018, from https:// www.investing.com/indices/idx-financehistorical-data

(n.d.). Retrieved July 22, 2018, from https:// www.investing.com/indices/idxinfrastructure-historical-data

(n.d.). Retrieved July 22, 2018, from https:// www.investing.com/indices/idxmanufacture-historical-data

(n.d.). Retrieved July 22, 2018, from https:// www. investing.com/indices/idxmiscellaneous-industry-historical-data

(n.d.). Retrieved July 22, 2018, from https:// www.investing.com/indices/idx-cons.property---real-estate-historical-data

(n.d.). Retrieved July 22, 2018, from https:// www.investing.com/indices/idx-tradeand-servic-histrical-data

(n.d.). Retrieved July 22, 2018, from https:// www.investing.com/indices/idx-30historical-data

(n.d.). Retrieved July 22, 2018, from https:// www.investing.com/indices/idx-banking- historical-data

(n.d.). Retrieved July 22, 2018, from https:// www.investing.com/indices/bisnis27historical-data

(n.d.). Retrieved July 22, 2018, from https:// www.investing.com/indices/idx-islamichistorical-data

(n.d.). Retrieved July 22, 2018, from https:// www.investing.com/indices/idx-mainhistorical-data

(n.d.). Retrieved July 22, 2018, from https:// www.investing.com/indices/idx-shariahhistorical-data

(n.d.). Retrieved July 30, 2018, from https:// www.investing.com/indices/investor33historical-data

(n.d.). Retrieved July 24, 2018, from https:// www.investing.com/indices/sri-kehatihistorical data

(n.d.). Retrieved July 30, 2018, from https:// www.investing.com/indices/mnc36historical-data

(n.d.). Retrieved July 30, 2018, from https:// www.investing.com/indices/sminfra18historical-data

Basher, S. A., Haug, A. A., \& Sadorsky, P. (2018). The impact oil-market shocks on stock returns in major oil-exporting countries. Journal of International Money and Finance.

Hamilton, J. D. (1989). A new approach to the economic analysis of stationary time series and the business cycle. Econometrica: Journal of the Econometric Society, 357-384.

Hamilton, J. D. (1990). Analysis of time series subject to changes in regime. Journal of econometrics, 39-70.

Hamilton, J. D. (1996). Specification testing in Markov-switching time-series models. Journal of econometrics 70.1, 127-157.

Hamilton, J. D. (2010). Regime switching models. In I. M. analysis, Regime Switching Models (pp. 202-209). London: Palgrave Macmillan.

Liu, J., \& Maheu, J. M. (2018). Improving Markov switching models using realized variance. Journal of Applied Econometrics, 297-318.

Roubaud, D., \& Arouri, M. (2018). Oil prices, exchange rates and stock markets under uncertainty and regime-switching. Finance Research Letters.

Uzoma, E. U., \& Florence, U. A. (2016). Application of Markov Switching Regression 
Model on Economic Variable. Journal of Statistical and Econometric Methods, 17-20.

Zhu, H., Su, X., You, W., \& Ren, Y. (2017). Asymmetric effects of oil price shocks on stock returns: evidence from a two-stage Markov regime-switching approach. Applied Economics, 2491-2507.

Zotoloy, L., Federickson, J. R., \& Lyon, J. D. (2017). Aggregate Earnings and Stock Returns: The Good, and The State-dependent. Journal of Banking \& Finance, 157-175. 